\title{
Carpal Tunnel Syndrome in Patients with and without Diabetes Mellitus in Upper Egypt: The Impact of Electrophysiological and Ultrasonographical Studies
}

\author{
Abeer A Tony ${ }^{1 *}$, Effat AE Tony ${ }^{2}$, Yasser ARM Selim ${ }^{3}$ and Ehab Saad ${ }^{4}$ \\ ${ }^{1}$ Departments of Neurology, Faculty of Medicine, Aswan University, Egypt \\ ${ }^{2}$ Internal Medicine, Assuit University, Egypt \\ ${ }^{3}$ Radiology, Faculty of Medicine, Aswan University, Egypt \\ ${ }^{4}$ Rheumatology and Rehabilitation, South-Vally University, Qena
}

"Corresponding author: Abeer Abdelhady Tony, Lecturer of Neurlogy, Department of Neuropsychiatry, Neurology unit, Faculty of Medicine, Aswan University, Aswan, 77777, Egypt, Tel: 097-3480901; 097-3480446; Fax : 097-3480449; E-mail : abeer.tony@aswu.edu.eg; abeer_tony70@yahoo.com

Received date: September 16, 2017; Accepted date: September 27, 2017; Published date: October 4, 2017

Copyright: (c) 2017 Tony AA, et al. This is an open-access article distributed under the terms of the Creative Commons Attribution License, which permits unrestricted use, distribution, and reproduction in any medium, provided the original author and source are credited.

\begin{abstract}
Introduction: Reports about median nerve CSA measurements between CTS patients with and without DM are actually scant. This study aimed to correlate the diagnostic accuracy of ultrasonography with electrodiagnosis in both DM and non-DM CTS patients. Patients and Methods: Thirty six non-diabetic patients and twenty five diabetic patients with CTS were assessed. All patients were subjected to electrophysiological assessment of wrists and grayscale ultrasonography (US).
\end{abstract}

Results: High mean cross sectional area of median nerve (CSA) on ultrasonography was detected with nonsignificant difference between both groups. A non-significant difference for flattening ratio was found between two groups. There was a highly significant positive correlation between electrodiagnosis and ultrasonography in diabetic patients.

Conclusion: The CSA of median nerve is larger in CTS hands in both DM and non-DM patients. The combination of electrophysiology and ultrasonography provides diagnostic effective tools across the entire spectrum of CTS in diabetic and non-diabetic patients.

\section{Key words:}

Carpal tunnel syndrome (CTS); Diabetes mellitus (DM); Diabetic polyneuropathy (DPN); Electromyography (EMG); Nerve conduction (NCS); Ultrasonography (US)

\section{Introduction}

Carpal tunnel syndrome (CTS) is the most common form of entrapment neuropathies [1]. Female gender, obesity, increase of age, hypothyroidism, pregnancy, rheumatoid arthritis, osteoarthritis and occupational factors like repetitive work are identified as the main risk factors for CTS [2]. Notably, diabetes mellitus (DM) is considered as a risk factor with a higher incidence of CTS in patients with prediabetes. A relationship between $\mathrm{HbAlc}$, duration of $\mathrm{DM}$, micro vascular complications and CTS had been stated [3]. Hendriks et al. [2] reported that although type 2 diabetes was more frequently diagnosed among patients with carpal tunnel syndrome, it could not be identified as an independent risk factor. The high prevalence of CTS among diabetic patients might be as a result of repeated undetected trauma, metabolic changes, accumulation of fluid or edema within the confined space of the carpal tunnel and /or diabetic cheiroarthropathy [4].

Electrodiagnostic studies (nerve conduction studies and electromyography) are useful in diagnosis of Carpal tunnel and its differentiation from cervical radiculopathy, diabetes or peripheral neuropathy [5]. Nerve conduction studies alone do not provide spatial information regarding the nerve or its attendant abnormalities [6]. Ultrasonography (US) has emerged as simple, low cost, rapid accurate and non-invasive imaging method for evaluating the median nerve in the carpal tunnel syndrome [7]. US have high sensitivity and specificity in CTS diagnosis. It can detect the median nerve compression characteristics, provide anatomical images of the median nerve, neighboring structures and space occupying lesions as ganglia neural tumors $[5,8]$. Therefore, US can be used in clinical evaluation of CTS in diabetic neuropathy [9].

Diabetes mellitus is a chronic metabolic disorder, which is characterized by persistent hyperglycemia with resultant morbidity and mortality in relation to its micro- and macrovascular complications. "The diabetic hand" is a term used to describe pathological hand manifestations that are more commonly found in diabetes. It represents the following musculoskeletal disorders; limited joint mobility, Dupuytren's contracture, flexor tenosynovitis and carpal tunnel syndrome. Combined occurrence of CTS and diabetes has been acknowledged for many years. Carpal tunnel syndrome (CTS) and diabetic polyneuropathy (DPN) are common conditions in patients with diabetes and therefore frequently occur concomitantly. Diagnosis of CTS in patients with DPN is important, as therapeutic interventions directed toward relief of CTS may be effective irrespective of diffuse neuropathy. The purpose of this study is to evaluate whether or not 
Page 2 of 5

ultrasonographic findings of the median nerve is different between DM and non- DM-CTS patients. To correlate the diagnostic results in both DM and non-DM-CTS patients.

\section{Patients and Methods}

This prospective study was conducted on sixty one patients $(122$ wrists : 51 females and 10 males), their ages ranged 23-82 years old (mean \pm SD $35.01 \pm 3.17$ years), referred from out-patients clinics of departments of Neurology, Orthopedic, Internal Medicine and Rheumatology and Rehabilitation, Aswan and Assuit University Hospitals, Aswan, Assuit, Egypt. All patients clinically diagnosed with carpal tunnel syndrome lasting for at least one month (Forty patients had bilateral CTS and Twenty one patients had unilateral CTS) in the period from January 2014 to December 2014 were included.The duration of illness ranged $6 \mathrm{~ms}$-10years old with mean \pm SD, $13.2 \pm 2.1$ years.For analysis purposes, The patients were classified into two groups according to Diabetes mellitus into thirty six non diabetic patients (group I), their ages ranged 14.7-68years old (mean age $35.7 \pm$ 12.8 years) and twenty five diabetic patients (group II), their ages ranged 14.7-68years old (mean age 34.1 \pm 13.9 years) (Table 1).

\begin{tabular}{|l|l|l|}
\hline Variable & Category & $\mathbf{N}=\mathbf{6 1}$ \\
\hline Age $($ Mean \pm SD) & $35.01 \pm 3.17$ & \\
\hline Sex & Male & $10(16.4 \%)$ \\
\cline { 2 - 3 } & Female & $51(83.6 \%)$ \\
\hline Laterality & Unilateral & $21(34.5 \%)$ \\
\cline { 2 - 3 } & Bilateral & $40(65.5 \%)$ \\
\hline Disease Duration in years (Mean \pm SD) & $13.2 \pm 2.1$ & \\
\hline
\end{tabular}

Table 1: Socio-demographic characteristics of the studied sample.

Exclusion criteria included pregnant women, those diabetic patients with clinical and electrophysiologic diagnosis of diabetic polyneuropathy, those with history of underlying disorders associated with CTS such as renal and hepatic diseases, patients with gout, rheumatoid arthritis or thyroid disease, patients with previous wrist surgery ( including carpal tunnel injection), and those with clinical or electrophysiological evidence of accompanying condition that mimics CTS as cervical radiculopathy. Clinical CTS was defined according to the criteria of the American Academy of Neurology practice parameters (reference). A written consent was obtained from all participants and approval from the local ethics committee of Faculty of Medicine, Aswan and Assuit Universities was obtained. All patients were subjected to full history taking, thorough clinical examination and neurological examination including (1) parathesia, pain provoked or worsened by sleep, sustained hand or arm position or repetitive action of the hand or wrist that is mitigated by a change in posture or by shaking of the hand (2) sensory deficit in median nerve distribution, (3) motor deficit of median innervated thenar muscles and (4) positive provocative tests for CTS (Tinel sign, Phalen test and Reverse Phalen test). The clinical diagnosis of CTSwas made when criterion 1 and one or more of criterion 2-4 were fulfilled [10,11]. Electrophysiological assessment of wrists and gray scale ultrasonography were done for all patients.

\section{Electrodiagnostic testing}

Electrophysiological assessment of wrists was done according to the recommended AAEM protocol using Neuropack XI/EMG/EP measuring system, MEB-2300 in the Neurophysiological unit, Neuropsychiatry Department, Faculty of Medicine, Aswan University. The Median nerve sensory action potential amplitude, latency and sensory conduction velocity $(\mathrm{CV})$ were measured. The Median nerve motor amplitude, distal motor latency (DML) and motor conduction velocity were measured by using standard techniques of supramaximal cutaneous stimulation and surface electrodes. F-response latency of median nerve was obtained to exclude proximal affection of the median nerve roots. Ulnar nerve sensory and motor conduction studies were performed. Needle EMG was done in abductor pollicisbrevis muscle to determine the severity of CTS and additional muscles in the upper limb to exclude proximal median nerve neuropathy, brachial plexopathy or radiculopathy. Measurements performed and cut-off points or normal values used in our study were as follows : (1) median nerve distal sensory latency, upper limit of normal $3.6 \mathrm{~ms}$ (2) distal motor latency over the thenar, upper limit of normal $4.3 \mathrm{~ms}$ (3) median motor nerve conduction velocity, lower limit of normal $49 \mathrm{~m} / \mathrm{s}$ (4) median sensory nerve conduction velocity, lower limit of normal $49 \mathrm{~m} / \mathrm{s}$. according to Delisa et al., 1994. The diagnostic criteria of electrodiagnostic tests for CTS were : Reduction in the median nerve sensory CV of less than $50 \mathrm{~m} / \mathrm{s}$, Prolongation of median nerve DML more than $4 \mathrm{~ms}$, No abnormalities in the proximal median nerve. The severity of electrophysiological CTS impairment was assessed according to the modified scoring system of Padua et al. [12].

\section{The ultrasonographic imaging analysis}

All patients underwent sonographic examination of the carpal tunnel. Both hands were examined. US examination was performed by using a $12 \mathrm{MHz}$ linear array transducer (Phillips, HD $11 \mathrm{XE}$ ), at the Radio diagnosis department at Aswan University Hospital. The sonographic examination was done at the same day or within days of the electrophysiological study. The median nerve was examined in the transverse and longitudinal planes along the carpal tunnel by gray scale US to investigate the presence of median nerve compression criteria, including the measurement of cross sectional area (CSA) and flattening ratio of median nerve. The cut-off value of cross-sectional area at the tunnel inlet was $9.5 \mathrm{~mm}^{2}$ Kang et al. [13].

\section{Statistical Analysis}

The collected data were verified, coded by the researcher, and then analyzed by the Statistical Package for Social Sciences (SPSS/PC/VER 21). Descriptive statistics: mean, standard deviation, median, range, frequencies, percentage were calculated. Test of significances: Chi square test was used to compare the difference in distribution of frequencies among different groups. Student t-test was calculated to test the mean differences in continuous variables between groups. Pearson's correlation co-efficient was calculated for parametric variables and Spearman's Ranked correlation co-efficient was calculated for non-parametric variables. Significant test results were considered when $\mathrm{p}$ value was $\leq 0.05$.

\section{Results}

The socio-demographic characteristics of the studied patients with carpal tunnel syndrome are presented in Table 2. 
Citation: Tony AA, Tony EAE, Selim YARM, Saad E (2017) Carpal Tunnel Syndrome in Patients with and without Diabetes Mellitus in Upper Egypt: The Impact of Electrophysiological and Ultrasonographical Studies. J Arthritis 6: 253. doi:10.4172/2167-7921.1000253

Page 3 of 5

\begin{tabular}{|l|l|l|l|}
\hline & $\begin{array}{l}\text { Non-diabetic } \\
(\mathrm{No}=36)\end{array}$ & $\begin{array}{l}\text { Diabetic } \\
(\mathrm{No}=25)\end{array}$ & P-value \\
\hline Age in years & $35.7 \pm 12.8$ & $34.1 \pm 13.9$ & $=0.647^{*}$ \\
\hline Female $\mathrm{n}(\%)$ & $30(83.3 \%)$ & $21(84.0 \%)$ & $=0.616^{* *}$ \\
\hline Disease Duration in years & $3.21 \pm 1.9$ & $3.12 \pm 2.3$ & $=0.860^{*}$ \\
\hline Laterality $\mathrm{n}(\%)$ & $23(63.9 \%)$ & $17(68.0 \%)$ & $=0.419^{* *}$ \\
\hline
\end{tabular}

*T-test analysis was used to compare the mean difference between the two groups

${ }^{* *}$ Chi-square Test analysis was used to compare the difference in proportions

--Significance level is considered when $p \leq 0.05$

Table 2: Baseline characteristics of the study participants.

Sixty-one patients were studied $(83.3 \%$ females and $16.7 \%$ males).Their ages ranged 23-82 years old (with mean \pm SD, $35.01 \pm$ 3.17 years). They were classified according to Diabetes Mellitus into two groups: group I were non- diabetic group ( thirty-six patients (59\%), with mean of age \pm SD $35.7 \pm 12.8$ years ) with the mean duration of disease was $3.21 \pm 1.9$ years, and group II were diabetic group (Twenty-five $(41 \%)$ with mean age \pm SD $34.1 \pm 13.9$ years ) with the mean duration of disease was $3.12 \pm 2.3$ years. A considerable number of patients $(40,65.5 \%)$ with or without diabetes mellitus demonstrated bilateral carpal tunnel syndrome with more prevalence in group I (57.5\%) of non-statistical importance. No statistically differences regarding the age, gender, increased duration of CTS or laterality between two groups.

Regarding electrodiagnostic studies of the median, a statistically significant difference between two groups was found in the CMAP, MNCV, DSL and F-wave of median nerve $(p<0.001,0.002,0.03$ and 0.04 respectively) as shown in Table 3 . CSA as well as FR of median nerve was larger in Non-DM-CTS-Hands and DM-CTS-Hands with no statistically difference between two studied groups as shown in Table 3.

\begin{tabular}{|c|c|c|c|}
\hline & $\begin{array}{l}\text { Non-DM-CTSHands } \\
(\mathrm{No}=36)\end{array}$ & $\begin{array}{l}\text { DM-CTS Hands } \\
(\mathrm{No}=25)\end{array}$ & P-value* \\
\hline \multicolumn{4}{|c|}{ Median Nerve } \\
\hline DML (ms) & $4.60 \pm 1.4$ & $4.21 \pm 1.3$ & 0.284 \\
\hline CMAP (mV) & $11.88 \pm 3.8$ & $9.57 \pm 4.2$ & $<0.001$ \\
\hline $\operatorname{MNCV}(\mathrm{m} / \mathrm{s})$ & $58.81 \pm 6.5$ & $52.63 \pm 6.3$ & 0.002 \\
\hline DSL (ms) & $3.19 \pm 0.3$ & $4.25 \pm 0.9$ & 0.028 \\
\hline $\mathrm{FW}(\mathrm{ms})$ & $25.60 \pm 3.3$ & $26.57 \pm 2.9$ & 0.041 \\
\hline \multicolumn{4}{|c|}{$\begin{array}{l}{ }^{*} \text { T-test analysis was used to compare the mean difference between the two } \\
\text { groups } \\
\text {--Significance level is considered when } p \leq 0.05 \\
\text { Abbreviations: NCV nerve conduction velocity, DML distal motor latency o } \\
\text { median, CMAP amplitude of median, MNCV motor NCV of median, DSL dista } \\
\text { sensory latency of median, FW median F wave }\end{array}$} \\
\hline
\end{tabular}

Table 3: Parameters of electrodiagnostic testing between Non -DM CTS and DM-CTS groups.

In diabetic patients with CTS, regarding the correlation between electrodiagnostic and sonographic results, there was statistically significant positive correlations between distal motor latency (DML) of median nerve and CSA ( $\mathrm{p}$-value $=0.003$ ). Moreover, there was statistically negative correlation between amplitude (CMAP), motor conduction velocity $(\mathrm{MNCV})$ and $\mathrm{FR}$ ( $\mathrm{p}$-value $=0.001$ and 0.023 respectively). Furthermore F-wave had statistically significant positive correlation with both CSA and FR ( $\mathrm{p}$-value $=0.035$ and 0.031 respectively). Interestingly, there was statistically positive correlation between the duration of DM and CSA but not with FR as shown in Table 4 and Figures 1-6.

\begin{tabular}{|c|c|c|c|}
\hline & $\begin{array}{l}\text { Non-DM- CTS- } \\
\text { Hands } \\
(\mathrm{No}=36)\end{array}$ & $\begin{array}{l}\text { DM-CTS Hands } \\
(\mathrm{No}=25)\end{array}$ & P-value* \\
\hline \multicolumn{4}{|l|}{ Median Nerve } \\
\hline CSA_D (mm2) & $10.27 \pm 2.5$ & $10.15 \pm 2.2$ & 0.186 \\
\hline Flattening Ratio & $3.50 \pm 0.5$ & $3.37 \pm 0.6$ & 0.389 \\
\hline \multicolumn{4}{|c|}{$\begin{array}{l}\text { *T-test analysis was used to compare the mean difference between the two } \\
\text { groups } \\
\text {--Significance level is considered when } p \leq 0.05\end{array}$} \\
\hline
\end{tabular}

Table 4: Parameters of ultrasonography among the groups.

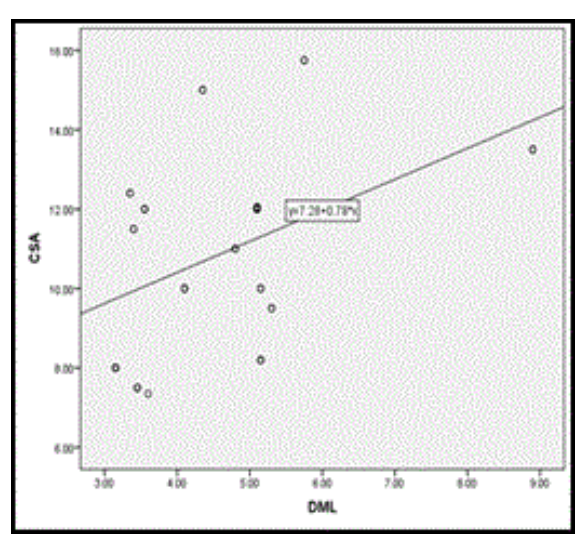

Figure 1: Correlation between CSA and DML.

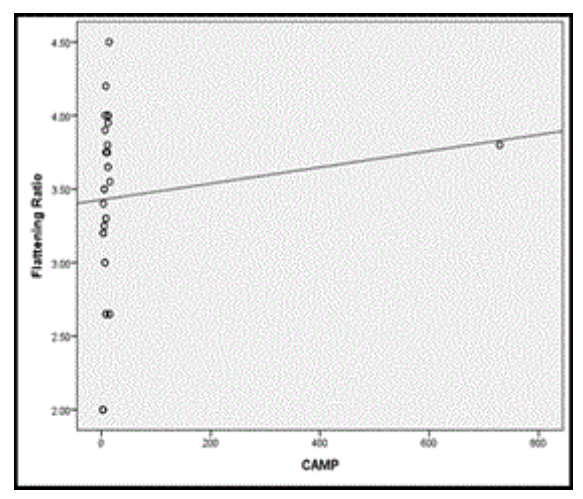

Figure 2: Correlation between Flattening Ratio and CMAP. 
Citation: Tony AA, Tony EAE, Selim YARM, Saad E (2017) Carpal Tunnel Syndrome in Patients with and without Diabetes Mellitus in Upper Egypt: The Impact of Electrophysiological and Ultrasonographical Studies. J Arthritis 6: 253. doi:10.4172/2167-7921.1000253

Page 4 of 5

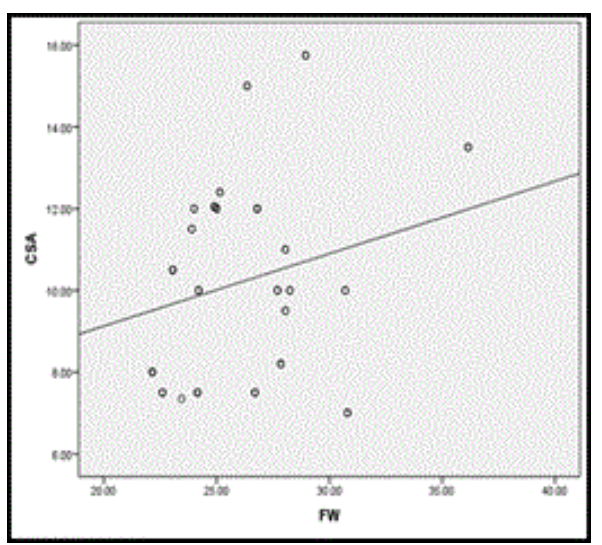

Figure 3: Correlation between Flattening Ratio and MNCV.

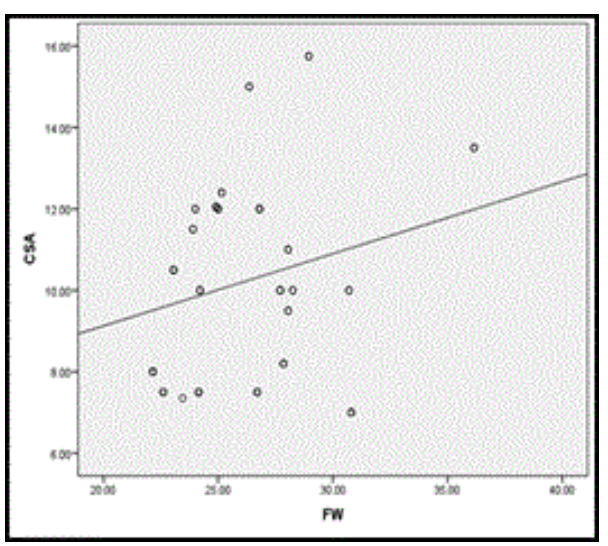

Figure 4: Correlation between CSA and FW.

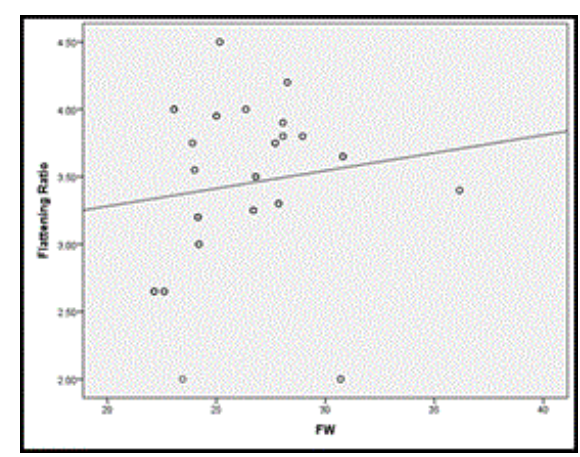

Figure 5: Correlation between Flattening Ratio and FW.

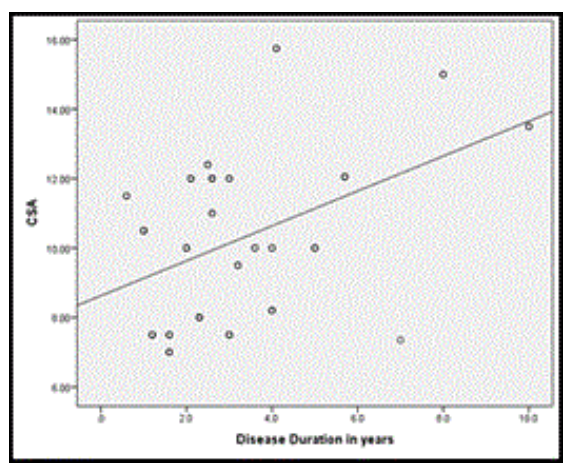

Figure 6: Correlation between CSA and DM Disease Duration.

\section{Discussion}

Carpal tunnel syndrome (CTS) is the commonest entrapment neuropathy and accounts for approximately $90 \%$ of all entrapment neuropathies with prevalence of approximately $3-6 \%$ of adults in the general population [5]. The reason as to why CTS is more common in diabetes is unknown and an early diagnosis is essential to prevent permanent nerve damage and functional squeals [7].

Confirmation of CTS is usually based on electrophysiological studies. However, many authors have proposed that conventional electrophysiological studies are not appropriate for detecting mild median nerve compression. Even when electrodiagnostic tests are applied, it is difficult to distinguish CTS from other neuropathic syndromes in diabetic patients [14-16]. Ultrasonography (US) has been used in clinical studies on diabetic neuropathy; however its use in the clinical evaluation of CTS in diabetic patients has not been reported [17]. To date, rare studies evaluated the value of ultrasonography (US) between diabetic and non- diabetic patients with clinical and electro diagnostic- confirmed CTS. In the current study, our results are consistent with previous studies of ultrasound in CTS in showing enlargement of median nerve in CT hands [18]. We found a larger measurement of CSA and FR of median nerve in studied patients when examined on both sides. However, we found no significant difference between diabetic and non-diabetic patients in measurement of CSAs. These findings could be explained by that the biological response to compression is the more important contributing factor rather than diabetic peripheral nerve injuries and the use of small sized sample of diabetic CTS patients in our study. Our finding was consistent with [19] who reported that the CSA of the median nerve was larger in both DM CTS and non-DM CTS groups compared to those without CTS. Agirman et al. [20] found larger median nerve CSA in diabetic patients with carpal tunnel syndrome at wrist levels compared with those of the healthy controls. Watanabe et al. [9,21] showed that the median nerve (at wrist) and tibial nerve (at the ankle) CSAs were increased in diabetic patients when compared with their control group. Moreover, we found increased FR in non-diabetic and diabetic group CTS patients without significant difference between both groups. These findings were in agreement with Tsai et al. [19], who revealed significantly larger measurement of CSA of median nerve in both non diabetic and diabetic patients. However, in contrast to our observations, Chen et al. [17] stated that the measured CSAs in both diabetic and DPN groups were larger than those measured in the idiopathic, non-diabetic and control groups. Moreover, our findings 
were in concordance with Boyaci et al. [22] who found statistically significantly greater FR in the DM-CTS groups than that of the control groups.

Among Diabetic patients with CTS, we showed highly statistically significant positive correlations of CSA with motor distal latency of median nerve. Moreover, both CSA and FR were significantly and positively correlated with F-wave latency of median nerve. These findings were in agreement with Watanabe et al. [9], who reported that the CSA in the carpal tunnel was correlated with delayed latency of median nerve. This arise the assumption that enlargement of the median nerve damages the myelin and results in the slowing of nerve conduction velocity. On the other hand, in agreement to our observation, Tsai et al. [19], revealed that the CSA of the median nerve positively correlates to the distal motor latency of the median CMAP and $\mathrm{F}$ wave while he revealed negative correlation between the measurements of CSA of the median nerve and the amplitude of the median CMAP suggesting that median nerve swelling contributes to axonal degeneration of the median nerve in CTS, in contrast to our results that found no correlation between CSA measurement, amplitude of the median nerve CMAP and the distal sensory latency of the median nerve.

This current study needs further studies and challenges. Several limitations should be mentioned: First, cases were only enrolled in a secondary care setting and thereby mostly severe cases were included. Thus, less severe CTS patients treated with conservative treatment by general practitioners did not participate in the current study. Therefore, the generalizability of our results is limited to secondary care. Furthermore, differential misclassification bias could have occurred because patients with the diabetic patients with suspected polyneuropathy by clinical presentation and have CTS should be excluded and they need further studies and evaluation. Third is that the association between the duration of diabetes and the electrophysiological and ultrasonographic findings should be considered. Finally, our number of cases is small so, more studies are needed and included larger number of cases.

\section{Conclusion}

The combination of electrophysiological and ultrasonography provides diagnostic effective tools across the entire spectrum of CTS in diabetic patients. Moderate to severe degrees of CTS and high mean CSA on ultrasonographical studies were characteristic patterns especially in diabetic patients. Moreover, there was a highly significant negative correlation between diabetic and non-diabetic patients evaluated by NCS and US. The prevalence of clinical CTS and the most efficient electro-diagnostic discriminators of CTS from diffuse neuropathy are uncertain. Nevertheless, screening for DM in patients with CTS is not recommended.

\section{References}

1. Werner RA, Andary M (2002) Carpal tunnel syndrome: pathophysiology and clinical neurophysiology. Clin Neurophysiol 113: 1373-1381.

2. Hendriks SH, Van Dijk PR, Groenier KH, Houpt P, Bilo HJG, et al. (2014) Type 2 diabetes seems not to be a risk factor for the carpal tunnel syndrome: a case control study. BMC Musculoskelet Disord 15: 346.

3. Singh R, Gamble G, Cundy T (2005) Lifetime risk of symptomatic carpal tunnelsyndrome in Type 1 diabetes. Diabet Med 22: 625-630.

4. Vinik A, Mehrabyan A, Colen L, Boulton A (2004) Focal entrapment neuropathies in diabetes. Diabetes Care 27: 1783-1788
5. Mohamed RE, Amin MA, Aboelsafa AA, Elsayed SE (2014) Contribution of power Doppler and gray-scale ultrasound of median nerve in evaluation of carpal tunnel syndrome. The Egy J of Rad and Nucl Med 45: 191-201.

6. Tai TW, Wu CY, Su FC, Chern TC, Jou IM (2012) Ultrasonography for diagnosing carpal tunnel syndrome: a meta-analysis of diagnostic test accuracy. Ultrasound Med Biol 38: 1121-1128.

7. Abdel-Ghaffar MK, El-sinnawy MA, Fawzy H, Ibraheem SE (2012) Gray scale and colour Doppler sonography in the diagnosis of carpal tunnel syndrome. Egy J of Rad and Nucl Med 43: 581-587.

8. Kim KU, Jeon HJ, Park SH, Park DS, Nam HS (2014) Value of ultrasonograhy in the diagnosis of carpal tunnel syndrome: Correlation with electrophysiological abnormalities and clinical severity. J Korean Neurosurg Soc 55: 78-82.

9. Watanabe T, Ito H, Morita A, Uno Y, Nishimura T, et al. (2009) Evaluation of the median nerve in diabetic patients: comparison with nerve conduction studies. J Ultrasound Med 28: 727-734.

10. You H, Simmons Z, Freivalds A, Kothari MJ, Naidu SH (1999) Relationships between clinical symptom severity scales and nerve conduction measures in carpal tunnel syndrome. Muscle Nerve 22: 497-501.

11. Jablecki CK, Andary MT, Floeter RG, Miller CA, Quartly A, et al. (2002) Practice parameter; electrodiagnostic studies in carpal tunnel syndrome: report of the American association of electrodiagnostic medicine, American academy of neurology, and the American academy of physical medicine and rehabilitation. Neurology 58: 1589-1592.

12. Padua L, LoMonaco M, Gregori B, Valente EM, Padua R, et al. (1997) Neurophysiological classification and sensitivity in 500 carpal tunnel syndrome hands. Acta Neurol Scand 96: 211-217.

13. Kang S, Kwon HK, Kim KH, Yun HS (2012) Ultrasonography of Median Nerve and Electrophysiologic Severity in Carpal Tunnel Syndrome. Ann RehabI Med 36: 72-79.

14. Perkins BA, Olaleye D, Bril V (2002) Carpal tunnel syndrome in patients with diabetic polyneuropathy. Diabetes Care 25: 565-569.

15. Yagci I, Gunduz OH, Sancak S, Agirman M, Mesci E, et al. (2010) Comparetive electrophysiological techniques in the diagnosis of carpal tunnel syndrome in patients with diabetic polyneuropathy. Diabetes Res ClinPract 88: 157-163.

16. Gazioglu S, Boz C, Cakmak VA (2011) Electrodiagnosis of carpal tunnel syndrome in patients with diabetic polyneuropathy. ClinNeurophysiol 122: 1463-1469.

17. Chen SF, Huang CR, Tsai NW, Chang CC, Chan WN (2012) Ultrasonographic assessment of carpal tunnel syndrome of mild and moderate severity in diabetic patients by using an 8- point measurement of median nerve cross-sectional areas. BMC Med Imaging 12: 15-24.

18. Bonder G (2008) Nerve compression syndromes. In: peer S, Bonder G (ediors): High-resolution sonography in peripheral neurvous system. 2nd ed. Spring Verlag, Berlin Heidelberg.

19. Tsai NW, Lee LH, Huang CR, Chang WN, Wang HC, et al. (2013) The diagnostic value of ultrasonography in carpal tunnel syndrome: a comparison between diabetic and non-diabetic patients. BMC Neurol 13: 65-72.

20. Agirman M, Yagci I, Leblebicier M A, Ozturk D, Akyuz GD (2014) Is ultrasonography useful in the diagnosis of the polyneuropathy in diabetic patients? J Phys Ther Sci 28: 2620-2624.

21. Watanabe T, Ito H, Sekine A, Katano Y, Nishimura T, et al. (2010) Sonographic evaluation of the peripheral nerve in diabetic patients: the relationship between nerve conduction studies, echo intensity, and crosssectional area. J Ultrasound Med 29: 697-708.

22. Boyaci A, Tutoglu A, Boyaci N, Koca I, Dokumaci DS, et al. (2014) An evaluation of radial and ulnar artery flow characteristics in diabetic patients with carpal tunnel syndrome and the diagnostic value of ultrasonography in these patients. J of Clin and Exp Invest 5: 179-185. 